\title{
ENSINO SUPERIOR EM TEMPOS DE COVID-19: CONJUNTURAS E PRÁTICAS
}

\section{Regina Helena Pires de Brito*}

(iD) https://orcid.org/0000-0002-0634-8572

\section{Maria Lucia M. Carvalho Vasconcelos**}

https://orcid.org/0000-0002-8775-9436

Como citar este artigo: BRITO, R. H. P de; VASCONCELOS, M. L. M. C. Ensino superior em tempos de Covid-19: conjunturas e práticas. Todas as Letras - Revista de Lingua e Literatura, São Paulo, v. 23, n. 2, p. 1-9, maio/ago. 2021. DOI 10.5935/1980-6914/eLETDO2114617

Submissão: junho de 2021. Aceite: junho de 2021.

Resumo: Em virtude da pandemia da Covid-19, todas as escolas do país - e do mundo - se viram obrigadas a enfrentar uma nova realidade: a do ensino remoto. Professores e alunos, diante da necessidade de um enfrentamento não planejado, sem tempo para reflexão prévia e com início imediato em todos os níveis de ensino, viram-se diante de uma realidade impensada. Este artigo afasta-se do ato de enumerar dificuldades vividas, o que seria absolutamente válido - dado o enorme esforço realizado e tudo o que se enfrentou e se está enfrentando neste período -, optando por narrar, com enfoque no ensino superior, experiências positivas que, certamente, muitas delas, perseverarão e terão continuidade após a volta para o ensino presencial.

Palavras-chave: Ensino remoto. Ensino presencial. Ensino superior. Experiências didático-pedagógicas. Diálogo expandido. 
Há algo que promete unir a humanidade diante do enfrentamento da Covid-19: a constatação de que o aprendizado é essencial para a nossa sobrevivência. Além do conhecimento científico ser a esperança para o encontro de uma vacina ou de um tratamento eficiente contra a doença, a suspensão das aulas presenciais na maioria dos países do mundo mostrou a importância dos espaços de construção do saber (CASATTI, 2020).

Em janeiro de 2020, a Organização Mundial de Saúde (OMS) alertava o mundo para a necessidade de se interromper a propagação do novo coronavírus que ameaçava a saúde global. A doença causada por ele, denominada Covid-19, teria surgido na China e, rapidamente, disseminou-se por todo o mundo, caracterizando-se, a partir de março de 2020, como uma pandemia.

Diversos países concentraram esforços na busca de vacinas que pudessem vir a interromper a onda de contaminações que assustava todos. Como medidas protetivas, algumas ações foram rapidamente assumidas como necessárias entre elas, o uso de máscaras, a constante higienização das mãos e o afastamento social.

A partir de então, muito se tem discutido, pensado e pesquisado a respeito da realidade pandêmica que todas as escolas do país - e do mundo - se viram obrigadas a enfrentar. Um enfrentamento não planejado, sem tempo para uma reflexão prévia e com início impreterivel. Professores e alunos, de todos os níveis de ensino, viram-se diante de uma realidade impensada, mas absolutamente necessária: a do ensino remoto.

Se as escolas, seus docentes e alunos estavam preparados, pouco importava. Era preciso fazer acontecer. O tempo não para e a criatividade, a dedicação e o esforço de todas as partes foram se implantando, com maior ou menor sucesso, mas com a única finalidade de se cumprir um período letivo que já se anunciava comprometido e pleno de dificuldades.

Poderíamos, neste artigo, enumerar as dificuldades vividas, o que seria absolutamente válido - dado o enorme esforço realizado e tudo o que se enfrentou e que se enfrenta neste período -, porém, optamos por narrar, com enfoque no ensino superior, algumas experiências positivas que, certamente, muitas delas, perseverarão e terão continuidade após a volta para o ensino presencial.

\section{O NOVO DIÁLOGO}

Que professor não sonha hoje com o dia em que nos reencontraremos com nossos alunos, nos espaços escolares? Rever os campi fervilhando de gente, de risos, de vida?

No espaço da sala de aula, professores e alunos constroem, em conjunto, um processo, chamado de ensino-aprendizagem, por meio do qual a educação escolar cumpre sua função. Conhecimento teórico, métodos e técnicas de ensino são acessados diariamente por docentes cujo papel profissional define-se pelo ato de ensinar.

Mas o que é o ensinar do professor se não houver o aprender do aluno? $\mathrm{Na}$ educação escolar, a ênfase deve recair sobre o aluno, sujeito da ação que ocorre nos espaços escolares. É para que o aluno aprenda e analise criticamente o aprendido que aulas acontecem e pesquisas se desenvolvem. Aprender o conhecimento cientificamente construído e criar novas perspectivas para esse 
conhecimento, alargando as possibilidades da ciência, são, afinal, o papel da universidade, quer seja em seus cursos de graduação, quer seja nos de pós-graduação.

Esse processo, o de ensino e de aprendizagem, deve ser de tal forma arquitetado pelo professor, o responsável pela gestão do espaço e do tempo de uma aula, que, ao longo de seu desenvolvimento, não haja mais uma dicotomia rigidamente hierarquizada na qual um fala e os demais, passivamente, ouvem, mas se transforme em um processo único, de ensino-aprendizagem, em que ambos os atores, docentes e discentes, se envolvam em torno de objetivos comuns, que, resumidamente, podemos afirmar serem a aprendizagem de ambos. Em sala de aula, todas as vozes importam na medida em que ali se constroem, num fazer diário que reúne diferentes saberes, experiências distintas e olhares díspares e que resultam no aprendizado tanto dos discentes quanto dos docentes. Aqui está a beleza do ensinar e aprender!

Se a autonomia do estudante é algo a ser perseguido no ensino superior (e não só nele), é preciso que condições democráticas de ensino e relacionamento sejam diuturnamente construídas. Dizia Paulo Freire (2001, p. 121) que a autonomia,

[...] enquanto amadurecimento do ser para si, é processo, é vir a ser. Não ocorre em data marcada. É neste sentido que uma pedagogia da autonomia tem de estar centrada em experiências estimuladoras da decisão e da responsabilidade, vale dizer, em experiências respeitosas da liberdade.

Assim, consoante com o que vimos neste texto afirmando, o diálogo entre professores e alunos, se é mandatório em todos os níveis de ensino, no ensino superior é absolutamente inquestionável.

Quando educadores e educandos realmente dialogam, a multiplicidade de vozes enriquece a tarefa docente, envolve o interesse discente, faculta a participação criativa de todos. Contudo, dialogar nem sempre é um ato natural a todo professor; requer uma intencionalidade por parte dele, sempre mais acostumado a falar do que a ouvir. Uma escuta atenciosa, aberta a revisões críticas de seu próprio pensamento, pronta a contra-argumentar com respeito, sem o ranço autoritário tão presente em nossas instituições. "[...] O diálogo é uma exigência existencial, [...] é o encontro em que se solidarizam o refletir e o agir de seus sujeitos, endereçados ao mundo a ser transformado e humanizado [...]" (FREIRE, 1987, p. 79).

Chegado o tempo da pandemia da Covid-19, vimo-nos, todos nós, professores, diante do desafio de dialogar com nossos alunos pela interface de uma tela de computador - não num modelo programado de educação a distância, pois fomos compelidos a ocupar o espaço digital para seguir com as atividades, mesmo aqueles que não tinham grande intimidade com plataformas e ferramentas virtuais. Como provocar a participação em aula de um aluno que não vejo (câmeras desligadas ou, até mesmo, inexistência de câmeras) e pouco ouço (entre falar, tendo que ligar o microfone e ser autorizado a usar da palavra para não interromper o outro, tornando impossível a compreensão do dito, muitos preferiam se calar)? As perguntas mais frequentes, por parte do professor, eram: "Você está aí?" e "Quem está falando?". O ritmo da aula era outro!

Com o tempo, todos foram se adaptando. O chat foi sendo incorporado. A combinação do uso de computador e celular também facilitou. Grupos no WhatsApp 
agilizavam a comunicação e alunos colaboravam com o professor e se ajudavam mutuamente. E, de repente, sem que nos déssemos conta, as aulas foram acontecendo com uma nova normalidade, um diálogo reformulado foi sendo construído e todo o processo foi ocorrendo. Como queriamos? Nem tudo. Totalmente inapropriado? Nem sempre. Apenas com resultados negativos? Certamente não!

Algumas experiências, inclusive, mostraram-se produtivas e é sobre elas que pretendemos conversar.

\section{E A SAla de aUla foi ampliada...}

As experiências que serão aqui apresentadas são relatos das nossas vivências como professoras da graduação e da pós-graduação em Letras da Universidade Presbiteriana Mackenzie, mas que podem ser facilmente replicadas e/ou cotejadas com o fazer didático-pedagógico de colegas de outras universidades.

O estudo do cotidiano escolar, segundo André (1989, p. 39),

[...] se coloca como fundamental para se compreender como a escola desempenha seu papel socializador, seja na transmissão dos conteúdos acadêmicos, seja na veiculação das crenças e valores que aparecem nas ações, interações, nas rotinas e nas relações sociais que caracterizam o cotidiano da experiência escolar.

Desde o momento em que a Universidade decidiu suspender suas atividades presenciais, em 12 de março de 2020, e orientou o corpo docente, discente e funcionários a permanecerem em isolamento social, a Instituição buscou oferecer a segurança necessária para o bom prosseguimento dos trabalhos de pesquisa, ensino, orientação, bancas e eventos diversos em seus diferentes programas de pós-graduação. Para isso, foram publicadas medidas para reorganizar as atividades do corpo docente e discente e da administração.

O Programa de Pós-Graduação em Letras (PPGL) aderiu às orientações administrativas e acadêmicas a partir do momento em que as atividades foram transferidas para o ambiente digital e, de imediato, do ponto de vista administrativo, foi fundamental a implementação de processos de depósito de qualificação e de defesa on-line em plataforma própria da Universidade e, com isso, toda a documentação passou a ser realizada no formato eletrônico, ou seja, passou-se à prática da tramitação eletrônica de todos os documentos de bancas, incluindo projetos de qualificação, dissertações, trabalhos de conclusão e teses para membros de bancas.

\section{ORIENTAÇões}

Seja na graduação, com a iniciação científica ou com o trabalho de conclusão de curso (TCC), seja na pós-graduação - lato ou stricto sensu -, orientar mostrou-se desde logo uma ação possivel e produtiva. Quer tenha ocorrido por meio de uma plataforma colaborativa específica (Microsoft Teams, Zoom, Google Meet, BigBlueButton [BBB] - Moodle ou outra), quer tenha ocorrido pelo celular, os contatos orientador-orientando se efetivaram com alta produtividade. Os horários mais flexíveis e a não necessidade de deslocamento foram fatores que concorreram para os bons resultados alcançados. 
A Instituição, desde o início do isolamento social, reforçou a disposição em acolher as demandas dos alunos e dos professores com qualquer dificuldade de acessibilidade. Nesse sentido, o PPGL mapeou alunos e professores eventualmente prejudicados por não disporem de todos os recursos ou conhecimentos necessários para acompanhamento e realização das aulas e das atividades acadêmicas avaliativas. Para minimizar a situação e contornar as dificuldades, foram disponibilizadas formas alternativas de acompanhamento e participação nas atividades acadêmicas, decididas caso a caso. É por essa razão que as orientações de alunos pós-graduandos puderam ocorrer apenas por meio das ferramentas on-line. O tipo de ferramenta foi escolhido em comum acordo entre o orientador e o discente, atendendo às condições de conectividade de ambos, para que a atividade de orientação e o desenvolvimento das pesquisas no mestrado e no doutorado não fossem bruscamente interrompidos ou prejudicados.

Deve ser ainda destacado que, como forma de minimizar o impacto da pandemia nas pesquisas desenvolvidas nos programas de pós-graduação, a Reitoria da Universidade vem concedendo três meses de prorrogação para depósitos de qualificação ou de trabalho final com isenção de taxas (inclusive para alunos pagantes) para os discentes prejudicados na etapa final de suas pesquisas, o que evitou pedidos de cancelamentos ou trancamentos de cursos, fato que impactaria negativamente a formação dos pós-graduandos e os próprios programas.

\section{BANCAS}

Assim como as orientações, as bancas ocorreram com igual tranquilidade. Os mesmos fatores facilitadores influíram para que o sucesso de tal prática se desse: horários flexiveis e a inexistência de deslocamentos. Desse modo, a realização on-line de todas as bancas de qualificação e defesa, com divulgação dos detalhes e acessos na página do Programa, garantindo a veiculação de informação sobre todas as sessões, possibilitou a presença de interessados de outras cidades, estados e até países, assistindo de modo síncrono às atividades desenvolvidas. As redes de contato e intercâmbio com universidades de todo o país e do exterior também puderam ser incentivadas, incluindo-se o alargamento das oportunidades de convites a professores de outras instituições, nacionais ou estrangeiras, enriquecendo muito o processo e expandindo as redes de contato interinstitucionais. Desse modo, apesar do estranhamento inicial causado pela transferência de todas as atividades para o universo digital, todas as defesas foram realizadas adequadamente e dentro do prazo previsto antes da pandemia; em suma, nenhuma atividade dessa natureza dos mestrandos ou dos doutorandos deixou de ser realizada durante a pandemia.

\section{Aulas}

As aulas da pós-graduação stricto sensu ocorreram em ambiente digital de forma sincrona, com o professor atuando ao vivo durante todo o período da aula normalmente previsto. Os docentes continuaram a disponibilizar os materiais de suas aulas (slides, conteúdos programáticos e outros materiais e atividades / tarefas) na plataforma Moodle, de forma que todos os discentes, independentemente das condições de conectividade com a internet, pudessem acessá-los em algum momento. Assim, as aulas ministradas em ambiente digital foram 
gravadas e compartilhadas posteriormente aos alunos para que ninguém fosse prejudicado por causa de algum problema eventual com sua conexão de internet. $\mathrm{O}$ BBB - Moodle foi o ambiente virtual de aprendizagem oficial da Instituição (já há muito tempo usado nos cursos EaD), embora os docentes pudessem recorrer a uma pluralidade de recursos para conduzir suas aulas síncronas (como outras plataformas colaborativas de comunicação), desde que acordado com suas turmas.

Os docentes disponibilizaram aos alunos, de acordo com o plano de cada disciplina e se necessário, atividades com acompanhamento e registro via Moodle e, ainda, a critério do professor, podiam ser adotados outros planos de estudos para melhor aproveitamento dos discentes. O corpo docente do Programa desenvolveu, também, atividades avaliativas por meio de diversos instrumentos e de propostas alinhadas às peculiaridades de cada disciplina e ao momento em questão, garantindo a integridade de cada aluno e docente.

\section{Atividades de divulgação de pesguisas e de conhecimento produzido NA ÁREA}

A pandemia provocou mudanças no modo de organizar os eventos acadêmicos. Em sua totalidade, os eventos do PPGL-UPM se adaptaram às demandas do momento excepcional de isolamento social e realizaram seus encontros no ambiente virtual, como a aula inaugural, jornadas ligadas aos grupos de pesquisa do Programa e a Mostra de Pós-Graduação em Letras. A seguir, apresentam-se as características e dados desses eventos.

O Programa manteve, portanto, em 2020, em novos formatos, os eventos que realiza anualmente e que estavam previstos antes mesmo da pandemia, como a Mostra de Pós-Graduação em Letras, a Aula Inaugural do Programa, e as jornadas dos grupos de pesquisa vinculados aos docentes do Programa: IV Jornada Mackenzie de Estudos Freireanos; XIII Jornada de Literatura Contemporânea; $5^{a}$ Jornada Bíblia e Literatura; IV Jornada de Estudos de Intermidialidade; VIII Encontro Mackenzie do Espaço Lusófono, e promoveu alguns novos no ano, como o programa semanal Diálogos PPGL.

Para que essas atividades, de fato, pudessem acontecer, foi criado, em junho de 2020, o canal do Programa no YouTube ${ }^{1}$, como uma plataforma de divulgação das diversas atividades on-line promovidas pelo PPGL, tais como como a Aula Inaugural do segundo semestre, as conferências de abertura e o encerramento da Mostra de Pós-Graduação em Letras, aulas especiais em disciplinas, as jornadas dos grupos de pesquisa e, principalmente, dos Diálogos PPGL.

O Diálogos PPGL é um programa on-line semanal criado durante a pandemia com o objetivo de estabelecer, como o nome indica, um diálogo (em linguagem menos formal) com professores convidados do Programa ou externos a ele (brasileiros e estrangeiros), considerados pesquisadores relevantes pela comunidade científica, tanto na área de Linguística quanto na de Estudos Literários, entrevistados por docentes do Programa. Iniciado em 25 de junho de 2020, foram realizados 24 episódios (23 regulares e um especial), que deram maior visibilidade ao PPGL, estreitaram o contato de seus docentes e discentes com pesquisadores diversos, (houve a participação de nove convidados de instituições de ensino

1 Disponível em: https://www. youtube.com/channel/UC7jIBOLiZU0vconqhM4e9Dg. Acesso em: 16 jul. 2021. 
superior [IES] do exterior), e contribuíram com a produção e a divulgação social do conhecimento produzido na área.

Dos vários eventos promovidos durante a pandemia da Covid-19, vale destacar, pela sua realização anual desde o início do Programa, a XXIV Mostra de Pós-Graduação em Letras, que ocorreu em ambiente virtual nos dias 4 e 6 de novembro de 2020. As conferências de abertura e o encerramento da Mostra, que foram realizados no canal do Programa no YouTube, possibilitando a participação do público externo à Universidade, foram proferidos por colegas de IES estrangeiras, da Universidade Paris Descartes e da Universidade da Costa Rica, o que provavelmente não teria sido possivel no modelo presencial. Por conta do uso dos instrumentos de comunicação digital, o evento teve participação significativa de 153 trabalhos orais e mais 91 inscritos como ouvintes. Dentre os trabalhos apresentados, 60 foram de alunos vindos de outras instituições brasileiras, o que representou um inédito alcance nacional para o evento. No encerramento do evento, foi possivel, ainda, o lançamento virtual de livro comemorativo de 20 anos do Programa - oportunidades antes não cogitadas, não fosse a conjuntura em que a pandemia nos colocou.

O canal do PPGL encerrou o seu primeiro ano de atividades com mais de 1.700 inscritos. O total de visualizações chegou a mais de 21 mil (somando mais de 6.500 horas de exibição), totalizando mais de 230 mil interações com nossos vídeos e com abrangência nacional, nas diversas regiões do país, e internacional, com registro de público em Costa Rica, Colômbia, Argentina, Peru, Portugal, Estados Unidos, França, Itália, Alemanha e Timor-Leste. Esses números, considerando-se a natureza do canal - vinculado a um programa de pós-graduação -, são significativos e representam o alto alcance propiciado, acentuando a visibilidade do Programa e tornando-o mais conhecido, por meio dessa ferramenta, cuja importância aumentou com o isolamento social, e contribuiu para a produção e a divulgação do conhecimento da área na sociedade.

\section{MOTIVAÇÃo PARA NOVOS PROJETOS}

Além da produção e circulação de conhecimento que os eventos on-line propiciaram no atual momento de pandemia, das aulas em novos formatos e orientações redesenhadas, a pandemia também fomentou a proposição de diversas pesquisas sobre os efeitos da Covid-19 e do isolamento social, por exemplo, no comportamento dos docentes do ensino básico, nas interações nas redes sociais, na organização discursiva das fake news e nas representações ficcionais que passaram a focalizar as complexidades do mundo "com" Covid-19.

Por fim, é imperativo mencionar a singularidade de 2020, ano marcado pela pandemia da Covid-19. Nesse ano dificil, a persistência e a criatividade foram as tônicas que movimentaram também cada ação do Programa de Pós-Graduação em que atuamos, na perspectiva do que afirmou Antonio Nóvoa (2020, p. 10), em entrevista à Revista Com Censo:

No início de 2020, o mundo foi surpreendido pela pandemia do Covid-19. De repente, o que era tido como impossível, transformou-se em poucos dias: diferentes espaços de aprendizagem, sobretudo em casa; diferentes horários de estudo e de trabalho; diferentes métodos pedagógicos, sobretudo através de ensino remoto; diferentes procedimentos de avaliação, etc. A necessidade impôs-se à inércia [...]. 
Com efeito, embora estivéssemos todos impactados e assombrados com a realidade global imposta pela Covid-19, fomos obrigados a rapidamente transformar nossas relações nos espaços do trabalho, nas ruas, nas relações familiares. Somos seres de mudança, "inconclusos", capazes de nos assumirmos "[...] como ser social e histórico, como ser pensante, comunicante, transformador, criador, realizador de sonhos, capaz de ter raiva porque capaz de amar [...]", como ensina Paulo Freire (2001, p. 46). Assim, tivemos que reagir e, no plano do trabalho, o primeiro desafio foi reorganizar as atividades de docentes e discentes, em consonância com as determinações institucionais e com a proposição de novas dinâmicas de aulas, defesas, orientações, atendimentos, reuniões, eventos. Também foram redimensionadas e intensificadas as formas de interação com alunos, professores, egressos, público externo e comunidade acadêmica em geral, com a criação de grupos específicos no WhatsApp e no Telegram, envio frequente de e-mails informativos e orientativos e publicação constante de comunicados via Instagram e Facebook. Na mesma direção, participamos - professores e alunos - de inúmeras lives, trouxemos para nossas aulas a participação de colegas de quatro continentes, consequências positivas de uma tragédia que ainda, no fechamento deste artigo, nos assusta.

Continuamos a sofrer perdas - próximas e distantes -, mas a insistência e a esperança nos fazem buscar as possibilidades do prosseguir nessa batalha, já que "[...] O futuro não nos faz. Nós é que nos refazemos na luta para refazê-lo" (FREIRE, 2000, p. 27). Foi essa convicção que nos moveu, também, a aproveitar o espaço deste artigo para compartilhar o positivo desta luta.

\section{Education IN UNIVERSITY DURING Covid-19 PERIOD: CIRCUMSTANCES AND PRACTICES}

Abstract: As a result of the pandemic caused by Covid-19, all schools in the country - and in the world - were forced to confront a new reality: remote learning. Teachers and students, dealing with the need for an unplanned confrontation, with no time for prior reflection and with an immediate start at all levels of education, are faced with an unthinkable reality. This article does not plan to enumerate the difficulties experienced during the Covid-19 period, which would be absolutely valid - given the enormous effort that has been made and everything that has been faced until now -, otherwise, this article narrates some positive experiences in the university that will certainly perdure after returning to a face-to-face learning.

Keywords: Remote learning. Presential learning. University education. Didacticpedagogical experiences. Expanded dialogue.

\section{REFERÊNCIAS}

ANDRÉ, M. E. D. A. A pesquisa no cotidiano escolar. In: FAZENDA, I. (org.). Metodologia da pesquisa educacional. São Paulo: Cortez, 1989.

CASATTI, D. Um guia para sobreviver à pandemia do ensino remoto. ICMC-USP, São Carlos, 7 maio 2020. Disponivel em: https: / / www.icmc.usp.br/noticias / 4917-um-guia-para-sobreviver-a-pandemia-doensino-remoto. Acesso em: 12 jun. 2021. 
FREIRE, P. Pedagogia do oprimido. 17. ed. Rio de Janeiro: Paz e Terra, 1987. FREIRE, P. Pedagogia da indignação: cartas pedagógicas e outros escritos. São Paulo: Editora da Unesp, 2000.

FREIRE, P. Pedagogia da autonomia: saberes necessários à prática educativa. Rio de Janeiro: Paz e Terra, 2001.

NÓVOA, A. A pandemia de Covid-19 e o futuro da Educação. Revista Com Censo: Estudos Educacionais do Distrito Federal, v. 7, n. 3, p. 8-12, ago. 2020. Disponível em: http://www.periodicos.se.df.gov.br/index.php/comcenso/article/ view/905. Acesso em: 12 jun. 2021. 